\title{
DEVELOPING A PUBLIC-PRIVATE PARTNERSHIP PERFORMANCE FRAMEWORK FOR TRANSPORT AND HEALTH SECTOR STAKEHOLDERS IN THE UK AND GHANA
}

\author{
Emmanuel Donkoh, Dr. Martina Murphy Dr. Robert Eadie
}

\begin{abstract}
Public Private Partnerships (PPP) have been used in the construction industry to deliver critical infrastructure projects in various sectors. PPPs performance improvement is a current stakeholder concern due to numerous project failures. This research compares PPPs transport and health sector infrastructure in the United Kingdom and Ghana to produce a sustainable performance improvement model. The research aim is twofold: first, to develop an empirical performance improvement model for PPP best practice implementation for the UK and Ghanaian transport and health sectors. Secondly, it will examine and compare the UK and Ghanaian PPP transport and health sector stakeholders' Critical Success Factors (CSF) and risks. A rigorous literature review on complex IPs was conducted into PPP transport and health sectors to identify stakeholders CSF and risks in infrastructure sector projects. Four (4) Delphi expert panels and statistical analysis will be used to identify the CSF and risks for successful implementation. The proposed research will establish valuable information for the public and private sectors' stakeholder interests when investing in transport and health infrastructure projects through PPP in both the UK and Ghanaian construction industries.
\end{abstract}

Keywords: Public Private Partnership, PPP, Transport, Health, Stakeholder management, Best practice.

\section{Introduction}

A major problem facing developed and developing countries is inadequate and unreliable infrastructure projects (IPs) [1]. However, IPs demand worldwide has increased creating an IP funding gap of about $\$ 1$ to 1.5 trillion yearly as of 2013 and this is predicted to continue until 2030 [2]. Furthermore, the universal financial crisis has put pressure on governments and institutions to invest in IPs to reduce the current IP investment gap. Inadequate and over age IPs are a critical problem in both developed and developing countries; two examples of which are the United Kingdom and Ghana [2]. Ghana, a developing nation, lacks adequate and reliable IPs to sustain its socioeconomic development agenda [3]. Whereas the UK is faced with over-aged IPs such as the 31,000-kilometre underground water pipes in London.

Emmanuel Donkoh, Dr. Martina Murphy and Dr. Robert Eadie Ulster University
Recent studies have established that $50 \%$ of these underground pipes are older than 100 years [4]. IPs project performance in the Ghana construction industry (GCI) has also been a major cause of concern amongst industry stakeholders and most importantly the Ghanaian Government (GOG) [5]. Similarly, the UK construction industry IP performance also has a history of stakeholders' disappointment [6]. As a result, various governments aiming to improve the process and project performance across IP's sectors have initiated industry reports [7]. Additionally, public IPs over the years has have been delivered using the traditional procurement [8]. Traditional procurement has led to massive cost and time overruns especially in the construction industry (CI) due to fragmentation, litigation, short-term project delivery, lack of trust and, absence of collaboration [9]. Furthermore, traditional project performance assessment criteria are inefficient and incapable of capturing and managing current increasingly complex IPs [10]. Analysing the performance challenges from above literature, it can be suggested that identified problems in both countries are similar and require immediate intervention. In addition, the Ghana construction industry practice was derived from the UK construction industry [7], therefore providing the key rationale for choosing the UK and Ghana for this study.

\section{Research Background}

To address the issues identified, it is proposed that successful CI IPs implementation depends on an appropriate and suitable procurement approach [11]. An alternative to traditional procurement is Public-PrivatePartnership (PPP) [8]. PPPs improve project stakeholders' relationships and timeliness of engagement [12]. PPPs IPs performance assessment is now a topical issue among public and private sector stakeholders worldwide [13]. Also, there are increasing stakeholders interested in PPPs comparative study to understand PPP similarities, risk and difference in developing PPP from different countries and different IPs sectors for production of a holistic policy guideline [14]. There is no adequate PPP country institutional characteristics comparison and factor ranking for successful implementation between developed and developing countries [15]. In addition, there is a lack of 
PPP comprehensive comparative studies between developed and developing countries and their IP sectors [16]. Furthermore, various PPP studies have been conducted but none of these have examined IPs sectors stakeholders' critical success factors (CSF) across different countries and sectors. In addition, existing studies on stakeholders' CSF only address general differences in stakeholders' CSF on PPP project implementation and the preparatory phase without considering PPP individual IPs sectors stakeholders CSF and risk management in detail [11]. PPP project management practice lacks empirical studies that seek to compare stakeholders interest and associated risk from different projects types or sectors. Even if there are some studies, they are not enough to evaluate individual projects or sector performance [17, 18]. PPP procurement systems lack holistic project risk management strategies based on IPs sectors and countries specifics, individual sector or project theoretical framework, project financial viabilities determinant model and appropriate procurement selection models [19]. There is no in-depth empirical case study or real-life projects and studies on processes that help improve risk management understanding in infrastructure projects. Furthermore, there no published studies that examine different projects or sector governance structures risk management influence that achieve different project outcomes [20]. There are also no comprehensive studies being done on particular projects or sector complexity and its impact on performance [21] creating a lack of knowledge in complex project management methods to deliver project objectives [22]. Advancing from the above gap in knowledge, the overall research aim is to produce PPP sustainable performance models; firstly, using empirical data to develop a performance improvement model for the UK and Ghanaian transport and health sector to produce best practice during implementation. Secondly, to use gathered empirical data to examine and compare PPP's in the UK and Ghana transport and health sectors in relation to stakeholders' critical success factors and risk, building on previous UK only work [55]. Again, stakeholders' risks and interests will also be compared with each country sector characteristics. Continuing from the introduction, there follows a literature review in the context of PPP transport and health sectors that considers country, sectors, stakeholders risk and interest and procurement impact on performance. The paper then discusses a proposed research method and analysis. The final section presents proposed research outcomes, impacts and future directions for research.

\section{Literature Review}

Project management ensures that sustainable project objectives are achieved after project completion [23]. Global inadequate resources and increase in population, aging and deteriorating IPs demand sustainable IPs management [24]. The relationship between project management and sustainability performance is current research focus in CI for future project management improvement [25]. However, effort has been placed on sustainable performance indicators (SPI) that satisfy project objectives, characteristics, associated risks and realistic valuation process $[24,25]$. Project sustainability performance enhances and promotes project value and benefits [23]. Sustainable IPs management results in a long term improvement in the $\mathrm{CI}$ as it involves various stakeholders with different interests, expectations and risks [26]. Stakeholder sustainability represents participation, involvement and management of key interests and risks. However, there is no guideline principles for assessing CI IPs country and sector performance [27]. Again, there is lack of knowledge for robust project performance improvement for decision makers [27]. Project performance can be realised throughout project implementation stages including financial, resources and skills, including, ideally, some ideologies or political considerations [28]. Unfortunately, project performance or success varies due to project contextual characteristics including contract or procurement used, project types and sector characteristics, stakeholder type and project funding and finance engagement [29]. In addition, PPP characteristics such as country, sectors, project, stakeholders and procurement type with holistic assessment can lead to sustainable PPP project performance [30]. Therefore, achieving sustainable performance in this research considers the associations between PPP IPs characteristics such country, sectors or project characteristics, stakeholders' types and appropriate procurement characteristics to achieve performance in transport and health sector projects. Again, sustainability in this research refers to managing various stakeholders' interests, expectations and risks in IPs life cycle performance indicates to achieve a common balance.

\section{Iv. Sustainable Performance Improvement Framework.}

PPPs IPs performance depends on country policy guidelines and institutional capacity [31]. IPs sectors are unique due to country and sector characteristics and requirements [32]. IPs performance requirements of individual sectors projects differ from sector to sector therefore requiring a different management approach [33]. However, proper policy guidelines and institutional establishments promote PPP implementation [34]. Arguably, PPPs implementation differs between different countries depending on country's institutional frameworks [35] and country characteristics [34]. The goal is to identify countries and sectors broader strategies that fit these country and sector characteristics [13]. Project success evaluations processes and its measurement differ, reasons are that different projects or sectors consist of different characteristics, and hence there is a lack of a single or agreed processes and methods for measuring project success using the same Key Performance Indicators (KPIs) [11]. Project success factors vary from project to project based on the project purpose and stakeholders' interests and risks [36]. Various IPs sectors have different risk issues with different stakeholder management processes [37]. PPPs procurement forms of project delivery systems involves various stakeholders, such as the traditional project delivery to achieve project 
objectives [38]. Project complexities, projects success, failure or poor performance can be associated with other factors including stakeholder's understanding of performance instead of the traditional performance characteristics [39]. Projects deliver stakeholder benefits which are the major drivers of project success. Therefore, achieving stakeholders' objectives in determining project success cannot be underestimated [40]. Private and public sectors interests differ from project to project and from different authority to another authority [11]. Furthermore, IPs cannot be successfully delivered without identifying and managing project stakeholders interest and risk [41]. IPs failure or success can be attributed to the selection of wrong procurement method and continuous use of a traditional performance framework particularly for public sector contracts [42]. Project performance can be achieved when a suitable project delivery method has been identified that corresponds to a project or sector and meets detailed definitions of all stakeholders' responsibilities [43]. Selection of procurement types is one of the key determinants of successful projects [28]. Project success can be achieved based on a holistic project management approach that addresses project-associated risk based on project sector characteristics. In addition, project success can be achieved when all potential success factors and risk has been well and adequately identified, measured and checked in all phases of project delivery process from project initiation to completion [44]. Unfortunately, present IPs performance measurement conceptualization is immature especially in relation to project types or it does not exist [17]. International CI IPs performance comparisons help improve different countries CI performance, capacity, productivity, growth, assessing size, stakeholders' performance and reliable overseas direct investment [45]. Furthermore, it assists policymakers, practitioners and large stakeholders in their decision especially for IPs investment [45]. In addition, the global CI market competitions have encouraged stakeholders in PPP IPs to produce cross-country and cross-sector performance comparisons [46]. PPPs project country or sector performance variations can be associated with institutional capacities and political influence leading to stronger or weaker PPP policy [15]. PPPs IPs success and failure depends on country policy guidelines and institutional capacity [31]. Poor performance of PPPs IPs countries and sectors is due to lack of systematic mappings of country and sector characteristics [47]. Studies on PPPs performance lack adequate country and sector comparisons especially for developed and developing countries [15]. PPP comparative studies will enhance quality implementation and best practice. Studies have discovered that PPPs comparative assessment on countries improves best implementation policies and development of institutional capacity to uptake PPPs in various countries [14]. PPP policy guideline and institutional buildings promote successful PPP throughout the world [48]. Arguably, PPPs implementation has evolved differently based on country's institutional capacity [49]. Similarly, governments have applied PPP differently to suite national development plan of individual countries [50].
Researching, developing performance indicators or benchmarks and learnings from other continent, countries and sectors are important for better understanding and improving project delivery to improve performance [27].

\section{v. Research Method}

The proposed research adopts a mixed methods approach underpinned by pragmatism philosophy where knowledge claims arise from actions, situations, and consequences [51]. In addition, this research further adopts an exploratory sequential method because there is no or inadequate or limited knowledge within a research problem. The proposed research process is grouped into three stages: (1) a Delphi panel approach, (2) a questionnaire survey and then (3) model development. A Delphi panel approach is mostly applied in decision making for predicting the future, formulating best practice and defining abstract perceptions of the problem [52, 54]. The Delphi panel approach processes are used to collectively gather consensus empirical information among groups of experts where there is little or inadequate information about a particular problem [53]. Expert panel formation will consist of identified stakeholder classifications from highways road transport and healthcare hospital building sectors in the CI from United Kingdom and Ghana. Selection of panel members will involve four (4) groups, one expert panel for each sector (Highways and Healthcare) and one for each country (UK and Ghana). The criteria for selecting panel members will be based on sector specialists with experience who are knowledgeable in both types of projects to supply or provide the necessary information. The role of these panel members is to confirm identified factors from literature or suggest additional factors that the literature review failed to capture for common agreement. Expert panel data gathering will focus on PPP transport and health country best practice, stakeholder's interests, risks and procurement risk identified from the literature. Data gathering is to obtain expert common opinion to develop a pilot questionnaire to establish stakeholders ranking of groupings of stakeholders' key risks, interests and country's best practice measure. The data collection process will involve rounds of questionnaires managed either by interview, email or other available and convenient means till Delphi experts agreed on consensus opinion. Nvivo ${ }^{\text {TM }}$ software will be used to analyse Delphi experts agreed consensus and quantitatively through the Delphi process analysis of the Likert scales of 1-5. The outcome then provides the data for the quantitative research. Data collection for quantitative analysis will adopt a pilot survey and a questionnaire survey as the primary source of data. The questionnaire data will be sourced from Delphi panel qualitative analysis. Questionnaire design and the pilot survey will be conducted to ensure suitability and comprehensibility in order to finalise the questionnaire. Accomplishing the research aim by comparing stakeholders' interests and risks, respondents (stakeholders) will be requested to provide answers in order to rank country's best practice factors, stakeholders' interests and risks from the two sector projects on a Likert scale of 1-5. Data will be imported into SPSS software for analysis. 
Mean value analysis (MVA) and Factor Analysis (FA) or Principle Components Analysis (PCA) will be used to calculate the comparative importance and explanation of respective stakeholders' performance success factors and corresponding risk. This will provide the weightings for the factors in the model. Healthcare and transport stakeholders project performance improvement model will be based on the weightings provided from the analysis determined in questionnaire. The model for this research will use stakeholders' critical success factors and risk factor will be built in Excel or an on-line application and then validated. The validation process will use the initial four Delphi groups to check that the model produces the expected results based on real life cases from those who formed the Delphi groups

\section{vi. Conclusions and Recommendation}

Sustainable project performance enhances the achievement of project goals involving project value and benefits in the area of economic, environmental and social sustainability [29]. The overall outcome of this study is to produce sustainable performance model for transport and health sectors stakeholders. As indicated already, sustainability in this study represents IPs life cycle performance indicating economic, social and environmental indicators to develop transport and health sectors stakeholders project performance framework for the UK and Ghana. The proposed framework of this study seeks to produce will categorise all stakeholders towards improving stakeholder interest and risk management in CI to improve project performance and the existing gap within PPPs IPs stakeholder investment management studies. Furthermore, it will help clarify and prioritized what critical success factors and key challenges are, which will be used to evaluate stakeholder management performance and finally identify areas for further improvement. In addition, the outcome will produce PPPs implementation policy guidelines and institutional structures to promote successful PPP implementation for the UK and Ghanaian transport and health sectors and other developed and developing countries. This will improve best implementation policies and the development of institutional capacity to support uptake of PPPs.

\section{Reference}

[1] Chou, J.S. and Pramudawardhani, D., 2015. Cross-country comparisons of key drivers, critical success factors and risk allocation for public-private partnership projects. International Journal of Project Management, 33(5), pp.1136-1150.

[2] Thierie, W. and De Moor, L., 2016. The characteristics of infrastructure as an investment class. Financial Markets and Portfolio Management, 30(3), pp.277-297.

[3] Chan, E.E.A.A.P. and Coleman, D.G.O.M.E., A fuzzy model for evaluating risk impacts on variability between contract sum and final account in government-funded construction projects.
[4] Hall, J.W., Henriques, J.J., Hickford, A.J., Nicholls, R.J., Baruah, P., Birkin, M., Chaudry, M., Curtis, T.P., Eyre, N., Jones, C. and Kilsby, C.G., 2014. Assessing the long-term performance of cross-sectoral strategies for national infrastructure. Journal of Infrastructure Systems, 20(3), p.04014014.

[5] Hackman, J.K., Agyekum, K. and Smith, B., 2017. Challenges to The Adoption of Knowledge Management in Civil Engineering Construction Firms in Ghana. Annals of the Faculty of Engineering Hunedoara, 15(1), p.87.

[6] Lam, T. and Gale, K., 2014. Highway maintenance: impact of framework agreements upon project financial performance. Construction Management and Economics, 32(5), pp.460-472

[7] Ofori-Kuragu, J.K., Baiden, B.K. and Badu, E., 2016. Key performance indicators for project success in Ghanaian contractors. International Journal of Construction Engineering and Management, 5(1), pp.1-10.

[8] Shen, S., Feng, X. and Peng, Z.R., 2016. A framework to analyze vulnerability of critical infrastructure to climate change: the case of a coastal community in Florida. Natural Hazards, 84(1), pp.589-609.

[9] Austin, R.B., Pishdad-Bozorgi, P. and de la Garza, J.M., 2015. Identifying and prioritizing best practices to achieve flash track projects. Journal of Construction Engineering and Management, 142(2), p.04015077.

[10] Zhu, J. and Mostafavi, A., 2017. Discovering complexity and emergent properties in project systems: A new approach to understanding project performance. International Journal of Project Management, 35(1), pp.1-12.

[11] Osei-Kyei, R. and Chan, A.P., 2017. Implementing public-private partnership (PPP) policy for public construction projects in Ghana: critical success factors and policy implications. International Journal of Construction Management, 17(2), pp.113-123.

[12] El Asmar, M., Hanna, A.S. and Loh, W.Y., 2013. Quantifying performance for the integrated project delivery system as compared to established delivery systems. Journal of Construction Engineering and Management, 139(11), p.04013012.

[13] Hickford, A.J., Nicholls, R.J., Otto, A., Hall, J.W., Blainey, S.P., Tran, M. and Baruah, P., 2015. Creating an ensemble of future strategies for national infrastructure provision. Futures, 66, pp.13-24.

[14] Verhoest, K., Petersen, O.H., Scherrer, W. and Soecipto, R.M., 2015. How do governments support the development of public private partnerships? Measuring and comparing PPP governmental support in 20 European countries. Transport Reviews, 35(2), pp.118-139.

[15] Matos-Castaño, J., Mahalingam, A. and Dewulf, G., 2014. Unpacking the Path-Dependent Process of Institutional Change for PPPs. Australian journal of public administration, 73(1), pp.47-66.

[16] Cheung, E., Chan, A.P. and Kajewski, S., 2010. The public sector's perspective on procuring public works projects-comparing the views of practitioners in Hong Kong and Australia. Journal of Civil Engineering and Management, 16(1), pp.19-32.

[17] Xia, N., Zhong, R., Wu, C., Wang, X. and Wang, S., 2017. Assessment of Stakeholder-Related Risks in Construction Projects: Integrated Analyses of Risk Attributes and Stakeholder Influences. Journal of Construction Engineering and Management, 143(8), p.04017030.

[18] Henjewele, C., Sun, M. and Fewings, P., 2014. Comparative performance of healthcare and transport PFI projects: Empirical study on the influence of key factors. International Journal of Project Management, 32(1), pp.77-87.

[19] Shi, S., Chong, H.Y., Liu, L. and Ye, X., 2016. Examining the Interrelationship among Critical Success Factors of Public Private Partnership Infrastructure Projects. Sustainability, 8(12), p.1313

[20] Guo, F., Chang-Richards, Y., Wilkinson, S. and Li, T.C., 2014. Effects of project governance structures on the management of risks in major infrastructure projects: A comparative analysis. International Journal of Project Management, 32(5), pp.815826

[21] Luo, L., He, Q., Xie, J., Yang, D. and Wu, G., 2016. Investigating the relationship between project complexity and success in 
complex construction projects. Journal of Management in Engineering, 33(2), p.04016036.

[22] Wager, T., 2015. Planning support systems for complex infrastructure development.

[23] Villalba-Romero, F., Liyanage, C. and Roumboutsos. A. 2015. "Sustainable PPPs: A comparative approach for road infrastructure." Case Studies on Transport Policy 3, no. 2 (2015): 243-250

[24] Umer, A., Hewage, K., Haider, H. and Sadiq, R., 2016. Sustainability assessment of roadway projects under uncertainty using Green Proforma: An index-based approach International Journal of Sustainable Built Environment, 5(2) pp.604-619.

[25] Silvius, A.J. and Schipper, R.P., 2014. Sustainability in project management: A literature review and impact analysis. Social Business, 4(1), pp.63-96.

[26] Kivilä, J., Martinsuo, M. and Vuorinen, L., 2017. Sustainable project management through project control in infrastructure projects. International Journal of Project Management.

[27] Vogl, B. and Abdel-Wahab, M., 2014. Measuring the construction industry's productivity performance: Critique of international productivity comparisons at industry level. Journal of Construction Engineering and Management, 141(4), p.04014085.

[28] Leviäkangas, P., Kinnunen, T. and Aapaoja, A., 2016. Infrastructure public-private partnership project ecosystem-financial and economic positioning of stakeholders. The European Journal of Finance, 22(3), pp.221-236

[29] Villalba-Romero, F. and Liyanage, C., 2016. Evaluating Success in PPP Road Projects in Europe: A Comparison of Performance Measurement Approaches. Transportation Research Procedia, 14, pp.372-381.

[31] Verhoest, K., Van Garsse, S., Van den Hurk, M., Willems, T. Akintoye, A., Beck, M. and Kumaraswamy, M., 2016. Developments of public private partnership in Belgium. Publicprivate partnerships: A global review, pp.45-58.

[32] Ekung, S., Siriwardena, M. and Adeniran, L., 2013. Optimised Selection and use of Project Procurement Strategy in Nigeria: A Case from Practise. Ethiopian Journal of Environmental Studies and Management, 6(6), pp.661-669.

[33] Rodríguez-Segura, E., Ortiz-Marcos, I., Romero, J.J. and TafurSegura, J., 2016. Critical success factors in large projects in the aerospace and defense sectors. Journal of Business Research, 69(11), pp.5419-5425.

[34] Van den Hurk, M., Brogaard, L., Lember, V., Helby Petersen, O. and Witz, P., 2016. National varieties of Public-Private Partnerships (PPPs): A comparative analysis of PPP-supporting units in 19 European countries. Journal of Comparative Policy Analysis: Research and Practice, 18(1), pp.1-20.

[35] Petersen, O.H., 2011. Public-private partnerships as converging or diverging trends in public management? A comparative analysis of PPP policy and regulation in Denmark and Ireland. International Public Management Review, 12(2), pp.1-37.

[36] Berssaneti, F.T. and Carvalho, M.M., 2015. Identification of variables that impact project success in Brazilian companies. International Journal of Project Management, 33(3), pp.638649.

[37] Erkul, M., Yitmen, I. and Çelik, T., 2016. Stakeholder Engagement in Mega Transport Infrastructure Projects. Procedia Engineering, 161 , pp.704-710

[38] Ogunsanmi, O., 2013. Effects of procurement related factors on construction project performance in Nigeria. Ethiopian Journal of Environmental Studies and Management, 6(2), pp.215-222.
[39] Doloi, H., 2012. Assessing stakeholders' influence on social performance of infrastructure projects. Facilities, 30(11/12), pp.531-550.

[40] Rajablu, M., Marthandan, G. and Yusoff, W.F.W., 2014. Managing for stakeholders: the role of stakeholder-based management in project success. Asian Social Science, 11(3), p.111.

[41] Eyiah-Botwe, E., Aigbavboa, C.O. and Thwala, W.D., 2017. Critical Success Factors for Enhanced Stakeholder Management in Ghana.

[42] Oyedele, L.O., 2012. Avoiding performance failure payment deductions in PFI/PPP projects: model of critical success factors. Journal of Performance of Constructed Facilities, 27(3), pp.283-294.

[43] Locatelli, G., Mancini, M. and Romano, E., 2014. Systems engineering to improve the governance in complex project environments. International Journal of Project Management, 32(8), pp.1395-1410.

[44] Wu, D.D. and Olson, D.L., 2013. Computational simulation and risk analysis: An introduction of state of the art research.

[45] Gruneberg, S. and Fraser, B., 2012. Construction purchasing power parities: potential roles and limitations. Building Research \& Information, 40(3), pp.348-356.

[46] Horta, I.M., Camanho, A.S., Johnes, J. and Johnes, G., 2013. Performance trends in the construction industry worldwide: an overview of the turn of the century. Journal of Productivity Analysis, 39(1), pp.89-99.

[47] Jooste, S.F. and Scott, W.R., 2012. The public-private partnership enabling field: evidence from three cases. Administration \& Society, 44(2), pp.149-182.

[48] Hodge, G. and Greve, C., 2010. Public-private partnerships: governance scheme or language game? Australian Journal of Public Administration, 69(s1).

[49] Petersen, O.H., 2011. Public-private partnerships as converging or diverging trends in public management? A comparative analysis of PPP policy and regulation in Denmark and Ireland. International Public Management Review, 12(2), pp.1-37.

[50] Verhoest, K., Carbonara, N., Lember, V., Petersen, O.H., Scherrer, W. and van den Hurk, M., 2013. Public Private Partnerships in Transport: Trends \& Theory P3T3. Discussion Papers part I, COST.

[51] Creswell, J.W., 2014. A concise introduction to mixed methods research. Sage Publications

[52] Haines, K.J., Kelly, P., Fitzgerald, P., Skinner, E.H. and Iwashyna, T.J., 2017. The Untapped Potential of Patient and Family Engagement in the Organization of Critical Care. Critical care medicine, 45(5), pp.899-906.

[53] Haines, S.T., Miklich, M.A. and Rochester-Eyeguokan, C., 2016. Best practices for safe use of insulin pen devices in hospitals: recommendations from an expert panel Delphi consensus process. American Journal of Health-System Pharmacy, 73(19 Supplement 5), pp.S4-S16.

[54] Murphy,M., Perera, S., and Heaney, G., 2015. Innovational Management Model: A Tool for Sustained Implementation of Product Innovation into Construction Projects. Construction Management and Economics. 33(3), pp.209-232

[55] Eadie, R., Millar, P., and Grant, R., 2013. PFI/PPP Private Sector Perspectives of UK Transport and Healthcare. Built Environment Project and Asset Management, 3(1),pp.89-104. 